\title{
Análise da Gestão dos Núcleos de Inovação Tecnológica (NITs): um diagnóstico empresarial usando o modelo de excelência em gestão para inovação organizacional
}

\author{
Analysis of the Management of Innovation Technology Centers: a \\ business diagnosis using the excellence model management for \\ organizational innovation
}

\author{
Márcia Cristina Tomaz Reina ${ }^{1}$ \\ Carlos Augusto Thomaz ${ }^{1}$ \\ Jorge Lima Magalhães ${ }^{2,3}$ \\ ${ }^{1}$ Universidade Federal do Rio de Janeiro, Rio de Janeiro, RJ, Brasil \\ ${ }^{2}$ Fundação Osvaldo Cruz, Manguinhos, Rio de Janeiro, RJ, Brasil \\ ${ }^{3}$ Universidade NOVA Lisboa, IHMT, Global Health and Tropical Medicine, Lisboa, Portugal
}

\begin{abstract}
Resumo
Os Núcleos de Inovação Tecnológica (NITs) são importantes para Inovação brasileira, proporcionando interface da academia, do mercado e das competências inseridas na Lei n. 13.243/2016. É necessário analisá-los à luz de um sistema eficiente e eficaz na excelência em gestão. Baseado no Sistema Nacional de Inovação, o trabalho objetivou analisar cinco NITs no Rio de Janeiro sob a perspectiva do Modelo de Excelência em Gestão (MEG). A pesquisa mensurou e analisou a gestão em prol da inovação. Resultados apontam média geral dos NITs com nota insuficiente em termos de maturidade de gestão em excelência. Conclui-se que a maioria dos NITs não apresenta nível de maturidade adequado. O MEG identificou as áreas e/ou os pontos para a elevação da maturidade de gestão e inovação organizacional. A perspectiva aponta para a capacidade de gerar impacto no desempenho dos NITs com inovação organizacional para vencer desafios e entraves na gestão eficaz em prol da Inovação.
\end{abstract}

Palavras-chave: Inovação Organizacional. Gestão Estratégica. Modelo de Excelência em Gestão.

\begin{abstract}
Technological Innovation Centers (NIT) are important for Brazilian innovation providing an interface between university, market and the competencies included in Law no. 13,243/2016. It is necessary to analyze them like an efficient and effective system for excellence in management. Based on the National Innovation System the work aimed to analyze five NIT in Rio de Janeiro from the perspective of the Management Excellence Model (MEG). The survey measured and analyzed management for innovation. Results point to general average of NIT with an insufficient score in terms of management maturity in excellence. It is concluded that the majority of NIT do not have an adequate level of maturity. The MEG identified the areas and/or points for increasing the maturity of management and organizational innovation. The perspective points to the ability to impact the performance of NIT with organizational innovation to overcome challenges and obstacles in effective management in favor of Innovation.
\end{abstract}

Keywords: Organizational Innovation. Management Excellence Model. Strategic Management.

Áreas Tecnológicas: Inovação. Gestão de NIT. Administração. 


\section{Introdução}

A inovação deve ser tomada como uma estratégia fundamental para o desenvolvimento econômico-social do país. Ela deve permear todos os atores envolvidos em seu sistema de inovação com atuação em todos os seus processos de forma eficiente (DRUCKER, 2016). A ausência de modelo ou de design organizacional que represente a inovação em sua perspectiva de processo gerido, de forma a ter mais evidências sobre as iniciativas pontuais que refletem as boas práticas de gestão nas organizações, é considerada um entrave para a inovação. A inovação para uma organização não se restringe à introdução de tecnologia, mas também em promover as mudanças organizacionais necessárias para o melhor empenho de sua atuação em gestão de inovação. (MARQUES et al., 2020).

Para Drucker (2016), uma organização inovadora requer diretrizes e práticas como estar; ser receptiva à inovação e inclinada a olhar a mudança como uma oportunidade e não como ameaça; ter a prática sistemática de medir o desempenho da organização e sua gestão em prol da inovação; e desenvolver o aprendizado integrado para melhorar o desempenho, ambos considerados obrigatórios, segundo o autor. Uma organização inovadora demanda práticas pertinentes para a estrutura organizacional, os recursos humanos adequados e sua gerência e para a remuneração, os incentivos e as recompensas.

Já Mintzberg (1987) enfatiza que a estratégia nas organizações modernas deve ser influenciada pelo ambiente e deve interagir com ele constantemente. Dessa forma, as organizações precisam reagir e adaptar suas estratégias às mudanças de cenário.

Segundo o Manual de Oslo (OCDE, 2005, p. 26), as atividades inovadoras de uma organização "[...] dependem tanto da variedade quanto da estrutura de suas interações com as fontes de informação, conhecimentos, tecnologias, práticas e recursos humanos e financeiros". Esse Manual considera quatro tipos de inovação: inovação de produto, inovação de processo, inovação de marketing e inovação organizacional. Para o desenvolvimento desse trabalho, convém definir e abordar o termo "inovação organizacional" como "[...] a implementação de um novo método organizacional nas práticas de negócios da empresa, na organização de seu local de trabalho ou em suas relações externas (OCDE, 2005, p. 61).

As inovações organizacionais visam à melhoria do desempenho de uma organização. Os aspectos peculiares da inovação organizacional se dão por meio da implementação de um método organizacional que seja o resultado de decisões estratégicas tomadas pela liderança ou pela gerência. As inovações organizacionais em práticas de negócios, por exemplo, significam a implementação de novos métodos para a organização dos processos de rotina e de procedimento para a condução do trabalho. Novos métodos organizacionais de uma organização compreendem a implementação de novos meios para organizar as relações com outras organizações/instituições (OCDE, 2005).

As inovações organizacionais não representam apenas um elemento de sustentação para os demais tipos de inovação (produto, processo, marketing), mas têm a capacidade de gerar um relevante impacto sobre o desempenho da organização. Além de atuarem na melhoria da qualidade e na eficiência do trabalho, ampliam o compartilhamento de informações e aprimoram a capacidade da organização ao saber fazer uso dos conhecimentos e tecnologias (OCDE, 2005). 
No Brasil, as empresas têm procurado inovar em seus processos, produtos e serviços. Para tanto, estão buscando parceiros para desenvolver pesquisas em inovação, com o intuito de melhorar todo o sistema de inovação da organização (CRUZ; OLIVEIRA; PAIXÃO, 2016; SILVA; FIGUEIREDO; MAGALHÃES, 2020).

Nesse cenário, emergem os Núcleos de Inovação Tecnológicas, já que eles são atores de inovação que contribuem na promoção, na utilização do conhecimento e no uso de novas tecnologias brasileiras vindas de universidades e de institutos de pesquisa (COSTA, 2013). No Novo Marco legal, a Lei n. 13.243 (BRASIL, 2016), eles são definidos como estruturas instituídas por uma ou mais Instituição Científica, Tecnológica de Inovação (ICT), podendo ter personalidade jurídica própria, tendo por finalidade a gestão de política institucional de inovação e com competências mínimas atribuídas pela Lei.

A mudança na Lei de Inovação ocorrida em 2016 criou o Código de Ciência e Tecnologia, a Lei n. 13.243, e aumentou as atribuições direcionadas aos Núcleos de Inovação Tecnológica (BRASIL, 2016). Antes, funcionavam apenas, em sua maioria, como escritórios de patentes nas universidades públicas. A partir dessa alteração, universidades comunitárias, privadas, centros de pesquisa e outras organizações passaram a ser também considerados Instituição Científica, Tecnológica de Inovação (ICT), status anteriormente conferido apenas para as universidades públicas. A mudança tornou obrigatório que nesses espaços também se constituam Núcleos de Inovação próprios (BROCKVELD, 2017).

Segundo o novo Marco Legal, Lei n. 13.243/2016, novas competências foram designadas aos Núcleos de Inovação Tecnológica e essas novas competências corroboram para uma atuação dos Núcleos de Inovação não apenas como escritórios de patentes, mas sim e fundamentalmente como escritórios estratégicos de negócios. As novas competências são: desenvolver estudos de prospecção tecnológica e de inteligência competitiva no campo da propriedade intelectual, de forma o orientar as ações de inovação da ICT; elaborar estudos e estratégias para a transferência de inovação gerada pela ICT; promover e acompanhar o relacionamento da ICT com as empresas; negociar e gerir os acordos de transferência de tecnologia oriunda da ICT; e representar a ICT pública no âmbito de sua política de inovação, uma vez que esta pode ser delegada ao gestor do Núcleo de Inovação Tecnológica (BRASIL, 2016).

Diante do exposto, os NITs se configuram como agentes de mudança na cultura organizacional para inovação em seus produtos e processos. Tidd e Bessant (2015) consideram que o sucesso de desenvolvimento de produtos e dos processos inovadores só serão possíveis se o contexto organizacional for favorável. Eles afirmam, ainda, que grande parte da pesquisa em inovação prevê que as estruturas organizacionais são influenciadas pela natureza das tarefas a serem praticadas dentro das organizações.

A origem etimológica da palavra "gestão" advém do latim, gestio, que significa ato de administrar ou de gerenciar; e de gerere, levar, realizar. Definir "gestão", no campo da administração ou da inovação, é colocar em prática um conjunto de ações previamente planejadas e organizadas com a finalidade de estas serem executadas de tal maneira que conduzam as organizações à maximização de seus resultados e objetivos (TIDD; BESSANT, 2015). 
Cavagnoli (2008 apud BELTRAME, 2014) menciona quatro pilares básicos pertencentes à gestão: planejar, organizar, dirigir e controlar. Esses pilares remetem ao ciclo PDCL (plan, do, check e learn), e esse ciclo é a melhor interpretação ou explicação para o funcionamento do Modelo de Excelência em Gestão (MEG).

O Modelo de Excelência da Gestão (MEG) surgiu como consequência de um estudo que buscou identificar o que as organizações de sucesso tinham em comum. Inicialmente realizado na década de 1980, a pesquisa identificou um conjunto de conceitos comuns a essas organizações. Importante destacar que, independentemente do tamanho ou do segmento, qualquer organização pode ser beneficiada pelo MEG (FNQ, 2016a; SEBRAE, 2013).

Nesse sentido, considerando a relevância do tema inovação para as organizações e a necessidade premente de elas alicerçarem a excelência de gestão nos seus processos e produtos, se torna urgente verificar a atuação dos NITs nesse processo, principalmente no que tange à liderança, à estrutura e aos planos, aos clientes, à sociedade, à informação e aos conhecimentos, às pessoas, aos processos e aos resultados.

\section{Metodologia}

A revisão bibliográfica foi realizada em bases de dados indexados, como Scopus, Web of Science, acessados pelo Portal de Periódicos da Coordenação de Aperfeiçoamento de Pessoal de Nível Superior (CAPES) e pelo Google acadêmico. No que se refere à busca por autores, foram pesquisados Bessant, Tidd, Schumpeter, Peter Druker, Prahalad, entre outros. No sistema de busca das referidas bases, foram realizadas pesquisas utilizando-se os seguintes temas: inovação, inovação organizacional, gestão estratégica da inovação, núcleos de inovação tecnológica, modelos de gestão dos NITs, modelo de excelência em gestão. A busca pelos artigos científicos publicados se deu nas bases indexadas.

A principal delimitação na elaboração deste trabalho foi em relação ao número da amostra de NITs disponíveis à época do presente estudo. Dos dez NITs consultados, cinco participaram em tempo hábil para a consolidação da amostra e da respectiva análise. Apesar de $50 \%$ de retorno, os dados obtidos não foram impeditivos para a obtenção do panorama de inovação tecnológica presente em cinco organizações atuantes no Estado do Rio de Janeiro.

Foi realizado o método quantitativo para levantamento dos dados. Para tanto, utilizou-se o questionário de autoavaliação do ciclo 2013 do Prêmio de Competitividade para Micro e Pequenas Empresas (MPE BRASIL) do SEBRAE/FNQ (2013) - o mesmo utilizado pelo Programa Agente Local de Inovação. Esse modelo tem o intuito de mensurar e de analisar a gestão em prol da inovação nas organizações.

O questionário tem como base o Modelo Excelência em Gestão da FNQ composto de 37 questões, com quatro opções de resposta, envolvendo os oito critérios de excelência em gestão do MEG. A estrutura do questionário pode ser observada na Figura 1. 
Figura 1 - Estrutura do questionário de autoavaliação da gestão

\begin{tabular}{|c|c|c|}
\hline & Critério & $\mathrm{N}^{0}$ de questöes \\
\hline \multirow{9}{*}{ GESTAKO } & Liderança & 6 \\
\hline & Estratégias e Planos & 4 \\
\hline & Clientes & 5 \\
\hline & Sociedade & 3 \\
\hline & Informaçoes e Conhecimento & 4 \\
\hline & Pessoas & 5 \\
\hline & Processos & 4 \\
\hline & Resultados & 6 \\
\hline & Total & 37 \\
\hline
\end{tabular}

Fonte: SEBRAE (2013)

Essas questões apresentam quatro opções de respostas (a, b, c, d) e externam uma ordem crescente de maturidade em cada aspecto. Por exemplo, a resposta D sempre representa maior maturidade no aspecto em relação às outras, e a resposta A representa menor maturidade, como o exemplo do Figura 2.

Figura 2 - Exemplo de questão do Diagnóstico MEG

\begin{abstract}
A MISSÃO DA EMPRESA ESTÁ DEFINIDA E É CONHECIDA PELOS COLABORADORES? A missǻ da empresa formaliza a razăo de sua existência, define por que ela existe. Usuaimente, a Missăo é estabelecida pelos dingentes no momento da criaçáo da empresa e pode ser revista sempre que necessária. O registro sob forma escrita e a comunicaçå da Missăo aos oclaboradores contribuen para que todos conheçam, compartinem e persigam os mesmos ideais, potencialzando a contribuiçăo de cada um na empresa.
\end{abstract}

\section{JUSTIFICATIVAS}

Apresentar a Missado da Empresa e os melos utilizados para a sua comunicaçào aos colaboradores. a. A Missão não está definida.

b. A Missão está definida informaimente, sendo do conhecimento apenas dos dirigentes.

c. A Missäo está definida e registrada sob a forma escrita e é conhecida e entendida por alguns colaboradores.

d. A Missāo está definida e registrada sob a forma escrita e é conhecida e entendida por todos os coleboradores.

Fonte: SEBRAE (2013)

Com relação à coleta das informações e de entrevistas, elas ocorreram nos meses de novembro de 2017 a junho de 2018. Por ser tratar de uma pesquisa cujo foco é a análise do potencial do uso do Modelo MEG por meio do Diagnóstico para uma gestão de excelência nos NITs, a designação desses NITs, no presente trabalho, foi realizada pelas nomenclaturas: NIT 1, NIT 2, NIT 3, NIT 4 e NIT 5, no entanto, os resultados não obedecerão à ordem sequencial das respectivas nomenclaturas. O nome das empresas não foi revelado, a fim de não expor as organizações, e os autores mantêm todos os dados sob sigilo para que sejam usados apenas para os fins científicos do presente trabalho. 


\section{Resultados e Discussão}

Diante da metodologia empregada, os resultados e discussões foram divididos em reflexões no campo da inovação organizacional e institucional dos NITs do Modelo de Excelência em Gestão e da análise dos dados dos núcleos de inovação tecnológica.

\subsection{Quanto à Inovação Organizacional e Institucional}

A inovação pode ser considerada como a busca, a descoberta, a experimentação, o desenvolvimento, a imitação e a adoção de novos produtos, processos e novas técnicas organizacionais (RISSARDI JÚNIOR; SHIKIDA; DAHMER, 2009). Sendo assim, a inovação é movida pela habilidade de estabelecer relações, detectar oportunidades e tirar proveito delas (TIDD; BESSANT, 2015). Além dos quatro tipos de inovação explicitados na introdução, Pellegrin (2015) apresenta um quinto tipo de inovação, classificada como inovação institucional, que não se encontra formalizada no Manual de Oslo, mas considera-se pertinente abordá-la neste trabalho.

Inovação institucional - é a implementação de uma nova visão, de uma nova missão, de novas diretrizes, de uma nova política, ou ainda de um novo marco regulador, que impacte o comportamento dos atores econômicos, seja em âmbito nacional, seja regional, seja setorial ou no âmbito interno das empresas. (PELLEGRIN, 2015, p. 57)

A inovação institucional significa um avanço para uma nova política-estratégica que envolva todas as partes interessadas (stakeholders), ou seja, uma nova estratégia embasada na "[...] qualificação das relações com fornecedores, clientes etc., [...] a construção de valor a partir de novas posturas em relação ao meio ambiente e à sociedade". (PELLEGRIN; ANTUNES JÚNIOR, 2015, p. 58)

Segundo Pellegrin (2015), esse quinto tipo de inovação diz respeito também a uma questão relevante que é a da ética e a da confiança nas relações. Esses elementos considerados institucionais são imprescindíveis e sine qua non no desenvolvimento das inovações organizacionais, principalmente as inovações relacionadas às parcerias, às alianças, às redes de organizações e às redes de inovação. Essas últimas consideradas fontes relevantes para potencializar as inovações tecnológicas.

Com a globalização da economia e a flexibilização dos formatos e das interações organizacionais envolvendo instituições, centros de pesquisa e agências governamentais, os economistas "neoschumpeterianos", como Chris Freeman, Giovanni Dosi, Richard R. Nelson e Sidney G. Winter, mudaram o enfoque de suas pesquisas para a formação e o desenvolvimento de redes. Um dos pontos de atenção da sociedade atual é o de disseminar o conhecimento científico produzido e, ainda, o de transformar esse conhecimento em inovação tecnológica. A promoção de um ambiente nacional favorável em alguns países, como Estado Unidos, a Alemanha e o Japão, viabiliza uma influência no estímulo às atividades de inovação. Estudos sobre esse "ecossistema nacional favorável" promoveram a criação do conceito de Sistema Nacional de Inovação (SNI) ${ }^{1}$ (VILLELA; PINHEIRO-MACHADO, 2013).

É a partir do entendimento da importância do processo de inovação que se compreende o Sistema de Inovação. O conjunto de atores que compõe o SNI constitui o quadro de referência

${ }^{1}$ Conjunto de instituições, atores e mecanismos em um país que contribui para a criação, o avanço e a difusão das inovações tecnológicas (VILLELA; PINHEIRO-MACHADO, 2013). 
no qual o governo forma e implementa políticas com o propósito de influenciar o processo inovativo (VILLELA; PINHEIRO-MACHADO, 2013).

Nos últimos anos, o Brasil obteve avanços significativos no Marco Legal que trata da inovação tecnológica. A Lei n. 10.973, de outubro de 2004 (Lei de Inovação), trouxe novas possibilidades de organização e de atuação das Universidades e Centros de Pesquisa que iniciaram a estruturação de Núcleos de Inovação Tecnológica para gerir a sua política de inovação, primeira competência imposta pela Lei de Inovação (BRASIL, 2004). A gestão de inovação pelos Núcleos de Inovação Tecnológica pode ser entendida como um fator de extrema relevância para a melhoria do progresso econômico e social (PEREIRA; MIGOSKY, 2016).

\subsection{Quanto aos Núcleos de Inovação Tecnológica}

O NIT poderá ser caracterizado em três perfis de acordo com as suas atribuições: o legal, o administrativo e o voltado aos negócios. Os Núcleos de Inovação, em sua maioria, têm atuado dentro do perfil administrativo e alguns de forma até insatisfatória (LOTUFO, 2009).

Desde a promulgação da Lei da Inovação, os Núcleos de Inovação se empenharam para assumir um papel fundamental e estratégico, não apenas em relação à gestão da Propriedade Intelectual da ICT, como também, e principalmente, no acompanhamento da relação universidade - empresa, negociando e gerindo acordos de transferência de tecnologia. Esse relevante papel e posicionamento dos NITs oriundos da Lei de Inovação impulsionou desde então o aumento de sua quantidade em várias instituições.

A questão principal e até o momento considerada um grande gargalo é a de que ao analisar os indicadores dos NITs/ICTs para o quesito transferência de tecnologia, constata-se que eles têm sido insatisfatórios na maioria dos Núcleos de Inovação do país.

De acordo com o Formulário para Informações sobre a Política de Propriedade Intelectual das Instituições Científicas, Tecnológicas de Inovação do Brasil (FORMICT) (BRASIL, 2017), as instituições que informaram apresentar contratos de transferência de tecnologia correspondem chegam ao um total de 58, a maioria representada pelas instituições públicas, ou seja, do total de ICTs (278), apenas $21 \%$ possuem algum tipo de contrato de transferência de tecnologia, principal meio de transferência do conhecimento acadêmico para o setor produtivo (Figura 3).

Figura 3 - Número de contrato de tecnologia entre Instituição Pública e Privada

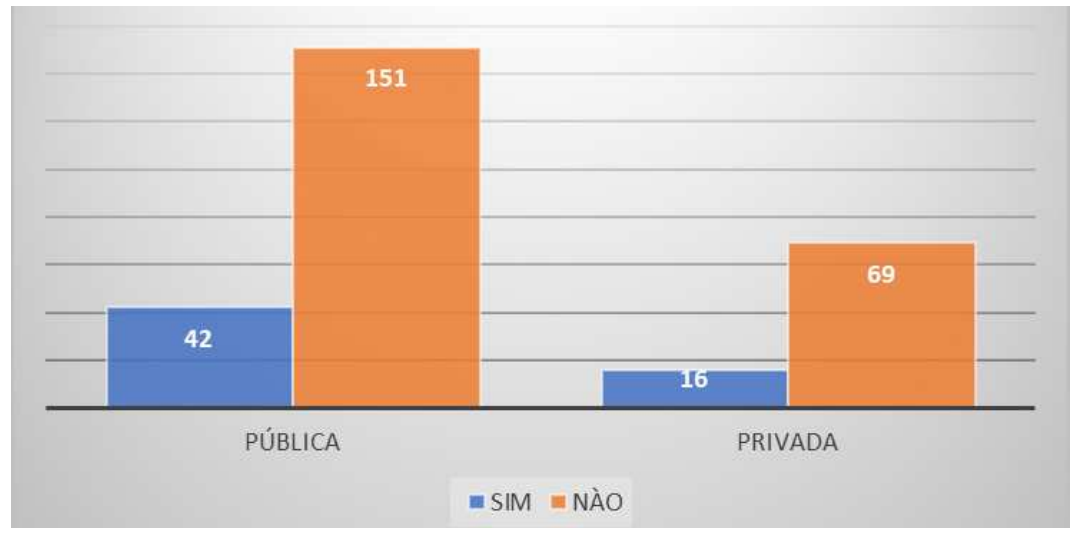

Fonte: Adaptada de Brasil (2017) 
Segundo Anversa (2017), a explicação para a maioria das ICTs realizarem tão poucos contratos deve-se ao fato de os NITs ainda se encontrarem no processo de busca do seu reconhecimento por parte das comunidades acadêmicas. Sendo assim, eles não possuem entendimento sobre isso, como também não há internalização dos conhecimentos relativos à transferência de tecnologia.

Esse delicado resultado aponta para um grande gargalo dentro do nosso Sistema de Inovação, impedindo o "giro" da tríplice hélice, e conclama a necessidade de revigorar e de até inovar as políticas relacionadas à transformação do conhecimento produzido nas ICTs em processos e produtos inovadores, com a finalidade de serem transferidos para o setor produtivo e, consequentemente, para o mercado.

Ao analisar as dificuldades, os diversos desafios que permeiam os ambientes (interno $e$ externo) dos NITs e os desafios que o futuro lhes reserva, convém disponibilizar aos NITs a oportunidade de analisar, rever e de aprimorar a sua gestão por meio de uma avaliação/diagnóstico, como o que está sendo abordado neste trabalho. Dessa forma, é relevante considerar o desempenho dos NITs e suas competências no âmbito de sua atuação (como elo entre academia e mercado) de forma eficaz e estratégica para a inovação no Brasil.

Nesse sentido, é imprescindível que os NITs atuem tomando como referência um modelo de gestão mais sistêmico, integrado e eficaz, alcançando, assim, resultados de excelência e se tornando mais sustentáveis e competitivos. Como afirma Cadori (2009, p. 117):

A organização e estrutura de um NIT vão ao encontro da organização e estrutura de um sistema vivo. A própria nomenclatura - núcleo - evidencia essa relação de dependência entre outras partes do sistema, mas ao mesmo tempo busca sua autonomia $e$ independência de funcionamento [...], se a organização e a estrutura desse núcleo não funcionarem de forma estruturada e independente, retardará o funcionamento de todo o sistema.

A gestão do NIT é um arcabouço de desafios e rica em complexidade, porém a sua gestão prescinde de excelência em sua atuação e de ser capaz de gerar resultados favoráveis a todas as partes interessadas e de forma sustentável em prol da Inovação.

Como toda organização, os NITs atuam em um ambiente em constante transformação que demanda agilidade, flexibilidade e melhoria contínua (CHIAVENATO, 2010; SOUZA, 2011).

\subsection{Quanto ao Modelo de Excelência em Gestão}

Segundo a Fundação Nacional da Qualidade (FNQ, 2013), o MEG reflete a experiência, o conhecimento e o trabalho de pesquisa de diversas organizações e de especialistas do Brasil e do Exterior. É uma metodologia de Diagnóstico para autoavaliação e/ou avaliação e reconhecimento das boas práticas de gestão.

O MEG é alicerçado por 11 fundamentos denominados Fundamentos da Excelência, que são: Pensamento sistêmico; Aprendizado organizacional; Cultura da Inovação; Liderança e constância de propósito; Orientação por processos e informações; Visão de Futuro; Geração de valor; Valorização das pessoas e desenvolvimento de parcerias; e Responsabilidade social. Já a 
respeito do conhecimento sobre a base teórica de uma boa gestão, percebe-se que esse conhecimento é traduzido em oito critérios de excelência: Liderança, Estratégias e planos, Clientes, Sociedade, Informações e conhecimentos, Pessoas, Processos e Resultados. Com isso, pode-se afirmar que os fundamentos, as organizações e o mercado são dinâmicos e atualizados de forma sistemática (FNQ, 2016a; SILVA; FILHO, 2020).

No modelo MEG (Figura 4), estão inseridos os oito critérios que são avaliados por meio do questionário. $\mathrm{O}$ entendimento e o funcionamento dele seguem o conceito PDCL, na seguinte lógica: os líderes (critério 1) definem as diretrizes organizacionais e estabelecem as estratégias e planos necessários (critério 2) para atender às necessidades dos clientes (critério 3) e da sociedade (critério 4) por meio dos processos (critério 7) efetuados por pessoas (critério 6) para o alcance dos resultados esperados (critério 8), de acordo com as informações e conhecimentos (critério 5) que vêm do ambiente interno e do ambiente externo.

Em 2016, a FNQ lançou a $21^{a}$ edição do MEG, alterando a sua figura, a de uma Mandala, para um Tangran (Figura 4).

Figura 4 - Modelo MEG

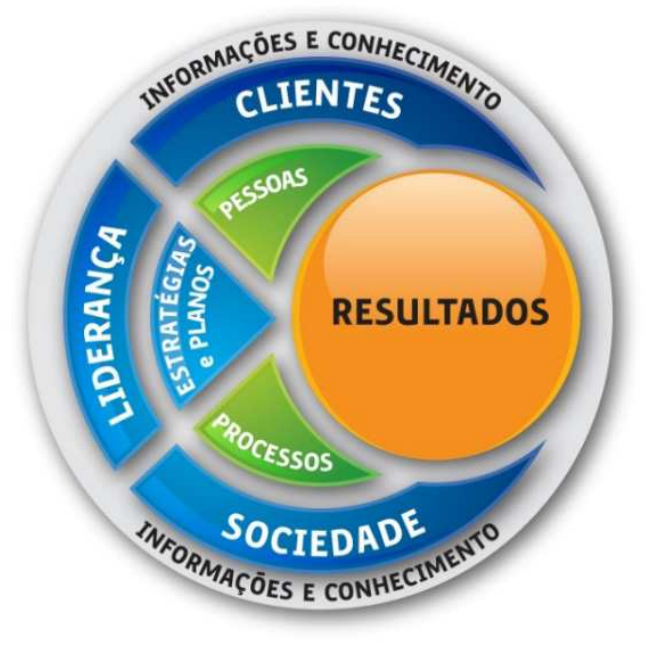

Fonte: FNQ (2013)

O MEG continua refletindo a complexidade do mundo da gestão. Sua principal característica é a "integração", principalmente por sua característica sistêmica (SILVA; FILHO, 2020).

O presente trabalho contribuirá de uma forma significativa para destacar a importância dos NITs como peça-chave e com uma atuação estratégica relevante para o processo de inovação no contexto do Sistema Nacional de Inovação (SNI).

O resultado será capaz de mostrar como os NITs podem atuar de uma forma mais eficaz, eficiente e com excelência para o aumento da competitividade do país e a ampliação dos benefícios para a sociedade e até para a própria gestão dos NITs.

Tomando como referência a relevância da atuação estratégica dos NITs para o processo de inovação no contexto do Sistema Nacional de Inovação, o objetivo geral deste trabalho consiste em analisar a gestão dos NITs sob a perspectiva do Modelo de Excelência em Gestão. 


\subsection{Quanto à Análise dos Dados dos Núcleos de Inovação Tecnológica}

Diante da relevância demonstrada do sistema de inovação nas organizações e, por conseguinte, o MEG para subsidiar os NITs na metodologia de diagnóstico estabelecida, foi possível estratificar radares com a metodologia aplicada. Dessa forma, para uma melhor análise dos dados e para facilitar a elaboração dos Radares, cabe informar que as pontuações originais de cada critério receberam um grau equivalente de zero a cinco (0 a 5). Portanto, a soma dos graus obtidos pelos respectivos NITs nos oito critérios revelará um conceito/classificação no desempenho de sua gestão na organização. Os respectivos radares permitirão identificar os pontos fracos da gestão, ou seja, quais os critérios que carecem de uma atenção maior e um aprimoramento com acuidade.

O Quadro 1 apresenta as pontuações obtidas por cada NIT participante do diagnóstico MEG em cada um dos critérios. Partindo do entendimento de que a pontuação máxima do grau de excelência em gestão que cada NIT poderia alcançar seria o somatório da pontuação máxima das questões referentes a cada critério $(5,0)$, perfazendo um total de 40 , é possível observar que dentro da amostra pesquisada dos cinco NITs, apenas o NIT 1 obteve o grau 26,56, o que equivale a cerca de $70 \%$ do grau máximo em excelência. Já o NIT 2, o NIT 3 e o NIT 5 obtiveram um grau aproximado, cerca de $40 \%$ do grau máximo dentro do diagnóstico MEG. Apenas o NIT 4 obteve um grau bem abaixo da média, o qual equivale a $22 \%$ do grau máximo possível.

Quadro 1 - Tabela Grau dos NITs referentes aos critérios do MEG

\begin{tabular}{|c|c|c|c|c|c|}
\hline CRITÉrIos & NIT 1 & NIT 2 & NIT 3 & NIT 4 & NIT 5 \\
\hline Liderança & 4,21 & 2,21 & 1,7 & 1,4 & 2,42 \\
\hline Estratégia e Planos & 3,5 & 0,75 & 0,75 & 0,75 & 2,25 \\
\hline Clientes & 2,85 & 1 & 2 & 0 & 1 \\
\hline Sociedade & 3,4 & 4,16 & 3 & 2,5 & 4,2 \\
\hline Informação e conhecimentos & 3,8 & 2,25 & 1,3 & 0,75 & 1,12 \\
\hline Pessoas & 3,1 & 1,5 & 1,7 & 1,2 & 2 \\
\hline Processos & 3 & 2,6 & 2,25 & 1,5 & 2 \\
\hline Resultados & 2,7 & 1,75 & 2 & 0,75 & 0,63 \\
\hline TOTAL & $\mathbf{2 6 , 5 6}$ & $\mathbf{1 6 , 2 2}$ & $\mathbf{1 4 , 7}$ & $\mathbf{8 , 8 5}$ & $\mathbf{1 5 , 6 2}$ \\
\hline
\end{tabular}

Fonte: Elaborado pelos autores deste artigo (2018)

Com a finalidade de se obter um melhor entendimento da dinâmica do movimento necessário que os NITs precisarão dar para que atinjam um nível maior de excelência na sua forma de atuação em gestão dentro do seu ecossistema, serão apresentados os resultados de cada um por meio de gráficos radares.

Ao observar a Figura 5, referente ao resultado do diagnóstico do NIT 1, nota-se que os critérios de excelência do MEG apresentam um grau de maturidade em gestão favorável, ou seja, acima de $60 \%$ do grau máximo em critério avaliado. Dessa maneira, percebe-se que os critérios de Liderança, Informações e Conhecimentos são os que mais se destacam entre os critérios avaliados, obtendo, respectivamente, grau 4,21 e 3,8. 
Figura 5 - Gráfico radar Diagnóstico NIT 1

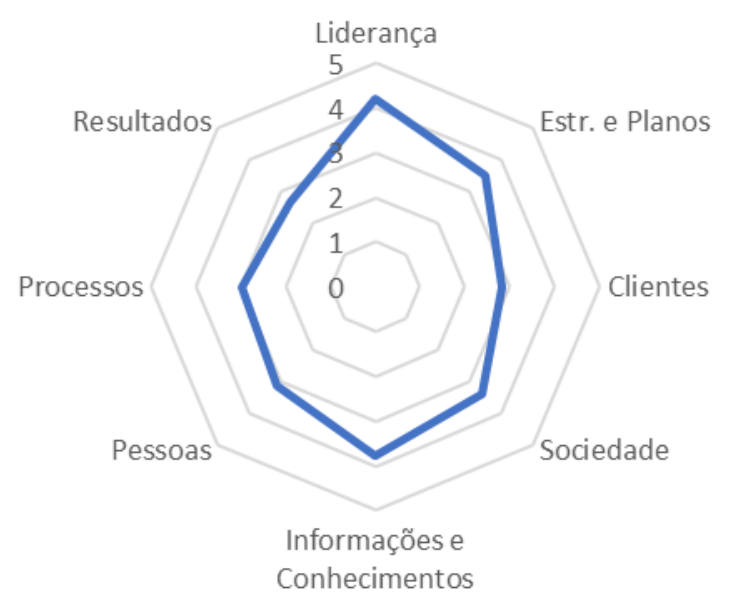

Fonte: Elaborada pelos autores deste artigo (2018)

O resultado do Diagnóstico MEG, apresentado no Radar 1, traduz com clareza que o NIT 1 adota uma prática sistêmica de gestão adaptável aos ambientes externo e interno, relacionando-se de forma integrada a todas as partes interessadas. O NIT 1 adota a prática de elaborar e revisar suas estratégias e planos, fazendo uso de indicadores definidos previamente (evidências constatadas durante a entrevista e diagnóstico). O NIT 1 possui 20 anos de atuação e pertence a uma instituição privada.

Ao analisar o NIT 3, nota-se que este possui aproximadamente 18 anos de existência e pertence a uma grande instituição pública. A Figura 6 reflete o grau de maturidade de excelência em gestão desse NIT. Em todos os seus critérios, ele obteve pontuação abaixo da média, exceto o critério Sociedade. O NIT 3 não possui a prática de definição de estratégias e planos, pois até a data não instituiu ainda a sua política de inovação, não mensura seus resultados e não faz uso de nenhum indicador. O resultado aponta, portanto, para um NIT que ainda não atua de forma sistêmica, harmoniosa e integrada em seu ambiente interno e externo. As evidências diagnosticadas indicam uma gestão que necessita de fortes transformações, aprendizados e melhorias.

Figura 6 - Gráfico radar Diagnóstico NIT 3

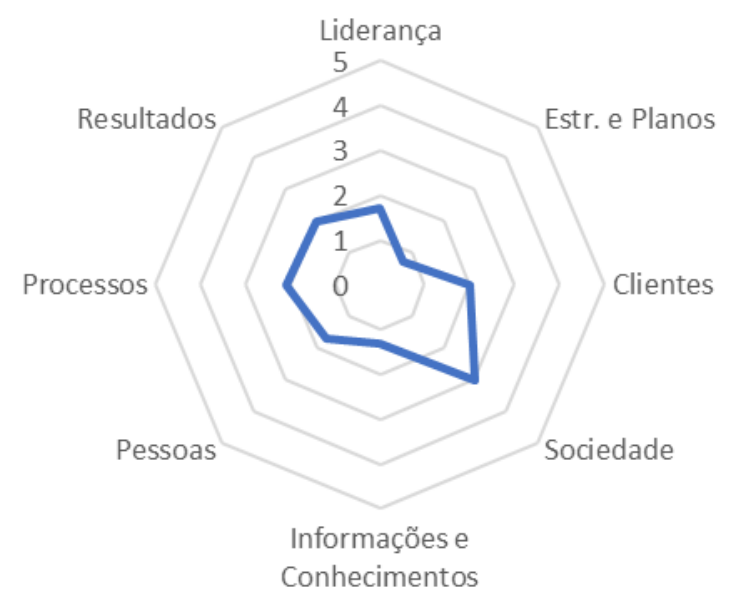

Fonte: Elaborada pelos autores deste artigo (2018)

O NIT 2, cujo tempo de existência é de aproximadamente 10 anos, tem o seu resultado demonstrado na Figura 7. Entre os critérios avaliados, o critério sociedade apresentou um 
excelente grau $(4,16)$. Tal resultado denota o cuidado e a preocupação com que o NIT procura identificar e satisfazer as necessidades e as expectativas da sociedade e das comunidades com as quais interage. Porém de acordo com o modelo de excelência em gestão (MEG), o NIT somente será capaz de alcançar a excelência em gestão quando passar a visualizar suas práticas de gestão de forma sistêmica, melhorando e avançando com os demais critérios.

Figura 7 - Gráfico Radar Diagnóstico NIT 2

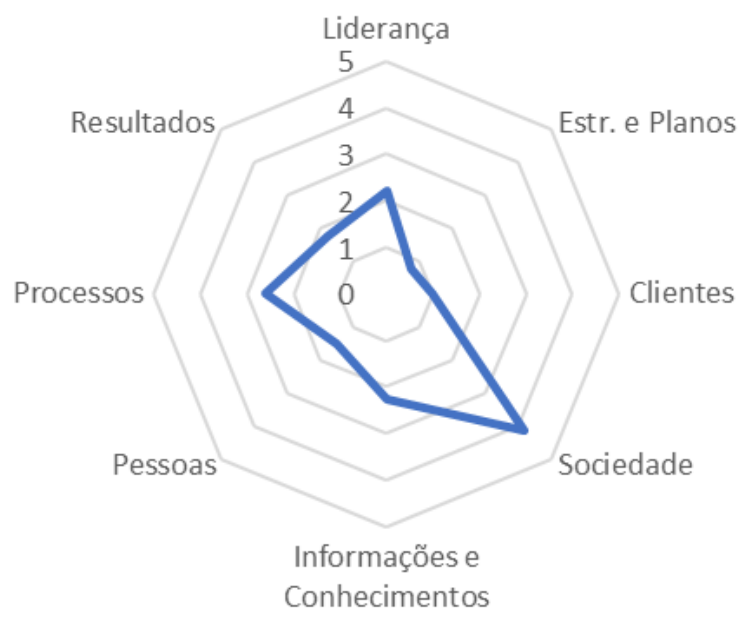

Fonte: Elaborada pelos autores deste artigo (2018)

A se analisar os resultados do diagnóstico realizado no NIT 5 (Figura 8), pode-se observar que entre os critérios avaliados, o NIT 5, tal qual o NIT 2, apresenta um excelente resultado no quesito Sociedade (Quadro 1). A gestão desse NIT, que pertence a uma instituição pública, tem investido esforços e elaborado estratégias em prol da inovação social pois tem procurado identificar as necessidades, e satisfazê-las, e as expectativas da sociedade e das comunidades com as quais interage.

Cabe destacar que o NIT 5, apesar de ter apenas dois anos de atuação, conquistou um resultado do diagnóstico MEG melhor do que o NIT 3 com 18 anos de atuação. Ressalta-se, ainda, que os critérios de Liderança e o critério de Estratégias e planos do NIT 5 foram respectivamente 2,42 e 2,25, em contrapartida, o do NIT 3 foi 1,7 e 0,75, respectivamente.

Figura 8 - Gráfico Radar Diagnóstico NIT5

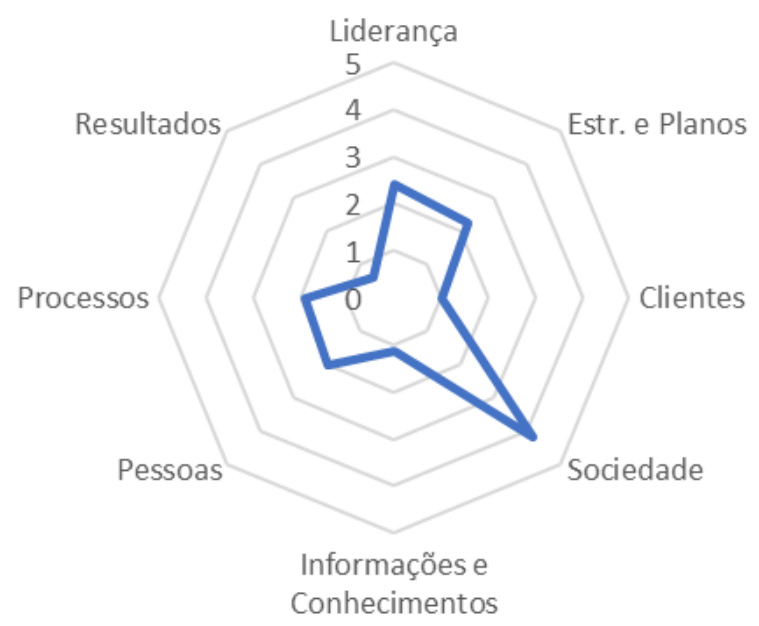

Fonte: Elaborada pelos autores deste artigo (2018) 
Em relação ao NIT 4, demonstrado na Figura 9, este foi o que obteve o grau mais baixo nos critérios de excelência em gestão avaliados pelo diagnóstico do MEG (Quadro 1). Esse NIT é pertencente a uma instituição pública e com nove anos de atuação. O NIT 4 só passou a existir pela obrigação da "força" da Lei de Inovação de 2004, segundo o seu respectivo gestor. O critério Resultados, que é referente a todas as partes interessadas e aborda os resultados de todos os processos da organização, recebeu o menor grau $(0,63)$. Um dos motivos para um grau tão baixo deve-se ao fato de o NIT 4 não fazer uso de indicadores para medir todos os resultados e, assim, deixando de monitorá-los. Pode-se inferir também a questão da baixa aderência ou até insuficiência para o entendimento no que o NIT 4 considerou "possuir estratégias e planos elaborados". Um outro ponto que se destaca é o grau recebido para o critério Clientes (0). Tal grau denota que o NIT 4 entende esse critério apenas sob a perspectiva do cliente externo, deixando, então, de perceber o cliente interno e seus pesquisadores principalmente.

Figura 9 - Gráfico Radar Diagnóstico NIT4

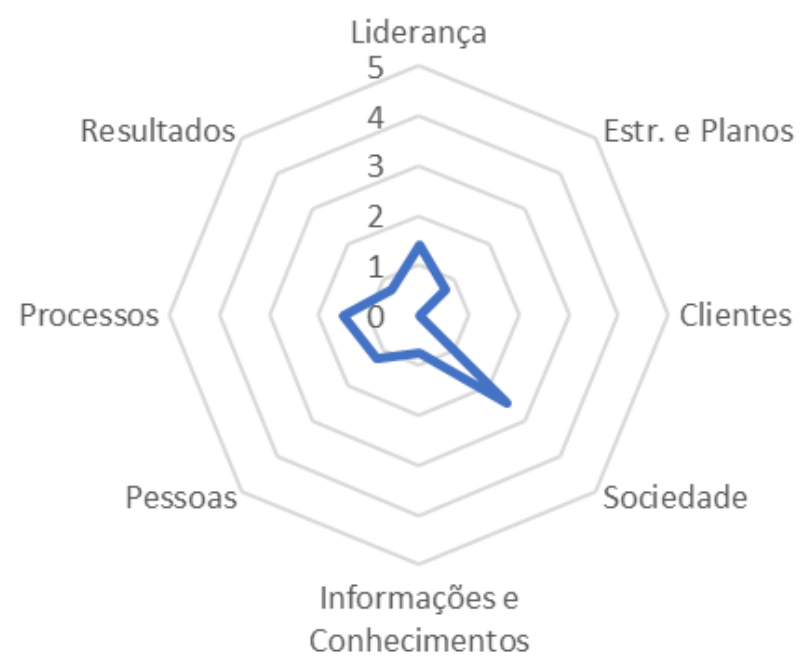

Fonte: Elaborada pelos autores deste artigo (2018)

Dos NITs analisados verificou-se quanto o NIT 1 se destaca e caminha em direção a uma gestão de excelência. O que comprova também que esse NIT apresenta uma maturidade em termos de gestão, capaz de exercer facilmente as novas atribuições dos NITs inseridas pela Lei n. 13.243/2016, chamada de Novo Marco Legal. É possível constatar também que a maioria dos NITs diagnosticados, com base no MEG, encontra-se ainda aquém de uma adequada maturidade em termos de gestão, não sendo, portanto, capaz de assumir suas novas, porém necessárias, atribuições em prol da Inovação.

Ao se realizar uma média geral de todos os NITs pesquisados em cada critério, visualizou-se uma imagem dessa insuficiência em termos de maturidade de gestão (Figura 10). 
Figura 10 - Gráfico Radar Diagnóstico dos NITs (média geral)

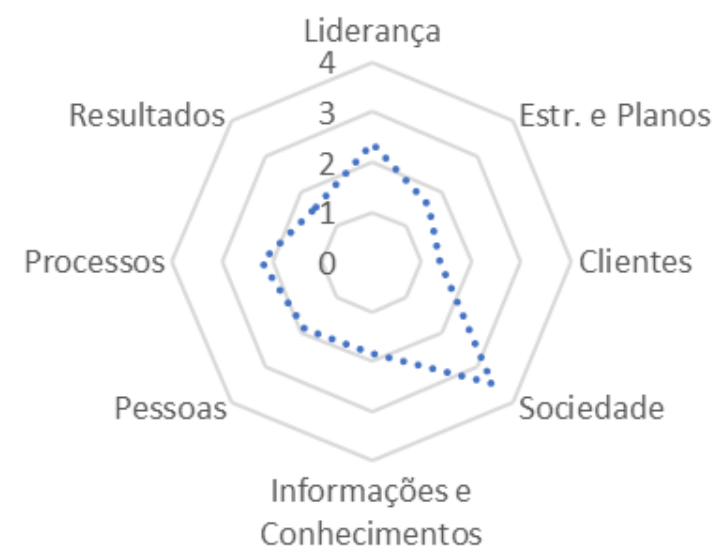

Fonte: Elaborada pelos autores deste artigo (2018)

Os resultados da "média geral" apontam a estrutura de gestão voltada para a sociedade, porém a orientação aos clientes é fragilizada, o que aponta uma dicotomia, uma vez que os clientes fazem parte da sociedade. Da mesma forma, a orientação para resultados e a informação e o conhecimento precisam ser retrabalhados. Logo, o sistema de gestão precisa de uma visão sistêmica na Gestão da inovação². Tidd e Bessant (2015) apresentam uma ferramenta de autoavaliação intitulada "Innovation-audit", nessa autoavaliação, eles analisam cinco categorias de uma organização, que são: Estratégia; Processos; Inovação organizacional; Redes e aprendizagem.

Essas questões que envolvem a categoria da Inovação Organizacional, inovação tecnológica e a propriedade intelectual para o avanço dos NITs dizem respeito à cultura da organização, ao desenvolvimento organizacional, ao compartilhamento de informações, ao fomento do intraempreendedorismo, à elaboração e revisão de estratégias, ao estabelecimento de parcerias e ao compartilhamento e entendimento de uma visão sistêmica e integrada da organização (CRUZ; OLIVEIRA; PAIXÃO, 2016).

Vale destacar que essas questões, que se referem à inovação organizacional, remetem aos fundamentos da excelência do MEG, a saber: Pensamento Sistêmico; Aprendizado organizacional; Cultura da inovação; Liderança e constância de propósitos; Visão de futuro; Desenvolvimento de parcerias; etc.

\section{Considerações Finais}

A principal ferramenta utilizada neste trabalho foi o Diagnóstico empresarial da gestão com base no Modelo de Excelência em Gestão (MEG), pois o objetivo principal foi analisar a gestão dos NITs localizados na Cidade do Rio de Janeiro sob a perspectiva dessa ferramenta.

Os resultados apresentados no presente trabalho evidenciam a necessidade de se realizar mudanças organizacionais por meio de uma melhoria e de desenvolvimento sistêmico de gestão, uma vez que se observa, ainda, instituições que instituem um NIT por força de lei e não o legitimam para atuar de forma a promover a inovação tecnológica em seus processos, produtos e serviços. 
Grande parte dos NITs analisados não apresenta um nível adequado de maturidade de Gestão em excelência. Por meio da ferramenta MEG foi possível identificar as áreas ou os pontos para a elevação da maturidade de sua gestão e, principalmente, a inovação organizacional necessária e premente. Essa inovação tem a capacidade de gerar um relevante impacto sobre o desempenho dos NITs conforme demonstrado pelos resultados obtidos.

Os NITs, como parte integrante da organização, se configuram como parte integrante dos ecossistemas complexos de inovação com os quais interagem e dependem, principalmente, de sua capacidade de perseguir seus propósitos em completa harmonia nesses ecossistemas.

Pelo que foi observado, o NIT que adota o MEG como referência de sua gestão é capaz de visualizar as práticas de gestão específicas que possibilitam uma atuação mais integrada $e$ sistêmica dentro do seu ecossistema de inovação e alcançam maiores e melhores resultados e, consequentemente, a excelência em gestão.

O critério Liderança dentro da metodologia do MEG é considerado, entre os demais avaliados no diagnóstico, aquele com uma pontuação/peso maior em relação aos demais critérios devido ao seu grau de importância. O MEG considera a Liderança responsável pelo estabelecimento e pela divulgação da Missão do NIT e, principalmente, pela análise do seu desempenho. Portanto, em todo e qualquer NIT como organização, o mais importante na construção de um sistema de inovação é a atuação de sua liderança, uma vez que é a sua visão que definirá se o NIT em sua plenitude percorrerá a trilha desafiadora e complexa da inovação.

\section{Perspectivas Futuras}

Considerando que a inovação deve fazer parte da essência da organização em todos os seus aspectos, é importante destacar que este trabalho não se limita ao que foi exposto, portanto, há possibilidades de trabalhos futuros em vários aspectos, por exemplo, replicar a presente metodologia numa amostra em organizações públicas e privadas separadamente, dada as respectivas características de cada área de atuação. Dessa forma, existe a possibilidade de comparar o cenário público separado do cenário privado. Não obstante, uma amostra por cada Estado da Federação e, por fim, uma amostra em caráter nacional.

Oportunidades de melhoria podem ser desenvolvidas a partir dos diagnósticos aqui apresentados para cada NIT participante. Os NITs com pontos fortes precisam se manter na vanguarda e trabalhar mecanismos para se tornarem atuantes de forma sistêmica onde apresentaram pontos menores. Da mesma sorte, os NITs com pontuações menores e também o NIT com menor grau atribuído necessitam rever seus processos internos de forma a ter uma aderência sistêmica da qualidade e da inovação tecnológica que perpasse da alta gerência ao colaborador da base de sua organização. Nesse sentido, oportunidades e desafios podem ser explorados no sentido de que, com o presente diagnóstico, possam ser construídos e/ou identificados, indicadores e ferramentas para auxiliar na condução da melhoria constante aos NITs após a aplicabilidade do MEG. 


\section{Referências}

ANVERSA, Marcus. A geografia das patentes e inovações tecnológicas com base nos Núcleos de Inovação Tecnológica (NITs). 1. ed. Curitiba: Prismas, 2017.

BELTRAME, Thiago Favarini. Análise da Cultura voltada a inovação em organizações rumo à excelência na região de Santa Maria - RS. 2014. 104f. Dissertação (Mestrado em Engenharia da Produção) - Universidade Federal de Santa Maria, Rio Grande do Sul, 2014.

BRASIL. Formulário para Informações sobre Política de Propriedade Intelectual das Instituições Científicas e Tecnológicas do Brasil (FORMICT) 2016. Brasília: MCTI, 2017.

BRASIL. Lei n. 10.973, de 2 de dezembro de 2004. Dispõe sobre incentivos à pesquisa científica e tecnológica no ambiente produtivo e dá outras providências. Disponível em: http://www.planalto. gov.br. Acesso em: 3 jan. 2018.

BRASIL. Lei n. 13.243 de 11 de janeiro de 2016. Dispõe sobre estímulos ao desenvolvimento científico, à pesquisa, à capacitação científica e tecnológica e à inovação. Disponível em: http://www. planalto.gov.br. Acesso em: 03 de jan. 2018

BROCKVELD, Marcos Vinicius V. De escritórios de patentes a escritórios de negócios. Via Revista, Florianópolis, v. 2, n. 3, novembro, 2017.

CADORI, Aluizia Aparecida. A visão sistêmica do ciclo de serviços de um núcleo de inovação tecnológica e o processo de transferência de tecnologia em uma instituição de ciência e tecnologia In: PROPRIEDADE INTELECTUAL, GESTÃO DA INOVAÇÃO E DESENVOLVIMENTO.

Propriedade Intelectual, Gestão da Inovação e Desenvolvimento. 1. ed. Passo Fundo, RS: Editora Imed, 2009. v. 1. p. 112-127.

CHIAVENATO, Idalberto. Iniciação à Teoria das Organizações. Barueri, SP: Manote, 2010.

COSTA, Carolina Oliveira Martins. Transferência de tecnologia universidade-indústria no Brasil e a atuação de núcleos de inovação tecnológica. São Paulo: Escola Politécnica da Universidade de São Paulo, 2013.

CRUZ, Cleide Ane Barbosa da; OLIVEIRA, Ilmara de Jesus; PAIXÃO, Ana Eleonora Almeida. Tecnologia e Propriedade Intelectual: parceiras nas atividades de Pesquisa e Inovação. Cadernos de Prospecção, Salvador, v. 9, n. 2, p. 175-185, abr.-jun. 2016.

DRUCKER, Peter F. O melhor de Peter Drucker: a sociedade. São Paulo: Nobel, 2002.

DRUCKER, Peter F. Inovação e espírito empreendedor: práticas e princípios. São Paulo, SP: Cengage Learning, 2016.

FNQ - FUNDAÇÃO NACIONAL DA QUALIDADE. Caderno Rumo à Excelência: introdução ao Modelo de Excelência em Gestão (MEG). São Paulo, SP: FNQ, 2013.

FNQ - FUNDAÇÃO NACIONAL DA QUALIDADE. Manual de Excelência da Gestão (MEG): Guia de Referência da Gestão para Excelência. 21. ed. São Paulo: FNQ, 2016a.

FNQ - FUNDAÇÃO NACIONAL DA QUALIDADE. \#24 Novo Modelo de Excelência da Gestão - MEG. São Paulo, SP: FNQ, 2016b.

LOTUFO, Roberto de Alencar. A Institucionalização de Núcleos de Inovação Tecnológica e a experiência da Inova Unicamp. Campinas, SP: [s.n.], 2009. 
SILVA, Saulo Moura; FIGUEIREDO, Tatiana. Aragão; MAGALHÃES, Jorge Lima de. Proposta para o alinhamento entre o plano estratégico institucional de um laboratório farmacêutico oficial e o departamento de TI. Revista Inovação, Projetos e Tecnologias, [s.l.], v. 8, p. 198-220, 2020.

SILVA, Hugo Filipy Bezerra Nunes; FILHO, Luis Cordeiro de Barros. Autoavaliação da Gestão Baseado no Modelo de Excelência Em Gestão ${ }^{\circledR}$ na Casa do Estudante de Pernambuco. Revista de Engenharia e Pesquisa Aplicada, [s.l.], v. 5, n. 3, p. 73-84, 2020.

MARQUES, Bartolomeu das Neves et al. Gestão da Inovação na Administração Pública Federal: reflexões sobre os caminhos, as barreiras e as perspectivas. Cadernos de Prospecção, Salvador, v. 13, n. 4, p. 1.069-1.087, setembro, 2020.

MPE BRASIL. Prêmio de Competitividade para Micro e Pequenas Empresas: Questionário de Autoavaliação, Ciclo 2013.

MINTZBERG, Henry. The Strategy Concept I: Five Ps for Strategy. California Management Review, [s.l.], v. 30, n. 1, p. 11-24, 1987. Disponível em: www.jstor.org/stable/41165263. Acesso em: 4 set. 2018 .

OCDE - ORGANIZAÇÃO PARA A COOPERAÇÃO E DESENVOLVIMENTO ECONÔMICO. Manual de Oslo: diretrizes para coleta e interpretação de dados sobre inovação. [S.l.]: FINEP, 2005.

PELLEGRIN, Ivan de; ANTUNES JÚNIOR, José Antonio Valle. Inovação: uma discussão conceitual a partir da perspectiva da cadeia de valor. In: PROENÇA, Adriano et al. (org.). Gestão da inovação e competitividade no Brasil: da teoria para a prática. Porto Alegre: Bookman, 2015.

PEREIRA, Reginaldo; MIGOSKY, Felipe. O papel dos Núcleos de Inovação Tecnológica na promoção da Inovação sustentável a partir do novo marco legal de ciência e tecnologia e inovação do Brasil, Florianópolis: CONPEDI, 2016.

PEREIRA, Reginaldo; MIGOSKY, Felipe. MEG na avaliação da Gestão de negócios. [S.l.: s.n.], 2013.

PEREIRA, Reginaldo; MIGOSKY, Felipe. Sobrevivência das Empresas no Brasil. Brasília, DF: [s.n], 2016.

RISSARDI JÚNIOR, Darcy Jacob; SHIKIDA, Pery Francisco Assis; DAHMER, Vanessa de Souza. Inovação, tecnologia e concorrência: uma revisita ao pensamento neoschumpeteriano. Revista Economia \& Tecnologia (RET), Paraná, v. 16, ano 5, jan.-mar. 2009.

SEBRAE - SERVIÇO BRASILEIRO DE APOIO ÀS MICRO E PEQUENAS EMPRESAS. Manuais do Curso de Capacitação do Programa Agentes Locais de Inovação. [S.I.]: SEBRAE, 2013.

SOUZA, Ana Clara Medina Menezes de. Gestão de Núcleos de Inovação Tecnológica. In: II CONGRESSO INTERNACIONAL IGLU, Florianópolis, 2011. Anais [...]. Florianópolis, 2011.

SOUZA, Crisomar Lobo de. Inovação e Mudança. In: BARROS NETO, João Pinheiro de; SOUZA, Gerson de (org.). Manual do empreendedor: de micro e pequenas empresas. Rio de Janeiro: Qualitymark Editora, 2012. p. 467-48

TIDD, Joe; BESSANT, John. Gestão da Inovação. 5. ed. Porto Alegre: Bookman, 2015.

VILLELA, Taís Nasser; PINHEIRO-MACHADO, Rita. Sistema nacional de Inovação brasileiro: principais características e acontecimentos históricos que permearam a sua formação. In: LAGE, C. L. S.; WINTER, E.; BARBOSA, P. M. da S. (org.). As diversas faces da Propriedade Intelectual. Rio de Janeiro: EdUERJ, 2013. p. 31-48 


\section{Sobre os Autores}

\section{Márcia Cristina Tomaz Reina}

E-mail:mrpsicoaching@gmail.com ORCID:http://orcid.org/0000-0003-4470-4002

Mestre pelo Profnit.

Endereço profissional: Rua Conquista, n. 280/102, Jardim Guanabara, Rio de Janeiro, RJ. CEP: 21931-170.

\section{Carlos Augusto Thomaz}

E-mail: carlos.augusto@ceditec.ufrj.br ORCID: http://orcid.org/0000-0002-0953-5824

Doutor em Direito.

Endereço profissional: Rua Moncorvo Filho, n. 8, Centro, Rio de Janeiro, RJ. CEP: 20211-340.

\section{Jorge Lima Magalhães}

E-mail: Jorge.magalhaes@far.fiocruz.br ORCID: http://orcid.org/0000-0003-2219-5446

Doutor em Ciências.

Endereço profissional: Rua Sizenando Nabuco, n. 100, Manguinhos, Rio de Janeiro, RJ. CEP: 21041-100. 